Note

\title{
SMALLEST REGULAR GRAPHS OF GIVEN DEGREE AND DIAMETER
}

\author{
MARTIN KNOR ${ }^{1}$ \\ Slovak University of Technology in Bratislava \\ Faculty of Civil Engineering, Department of Mathematics \\ Radlinského 11, 81368 Bratislava \\ e-mail: knor@math.sk
}

\begin{abstract}
In this note we present a sharp lower bound on the number of vertices in a regular graph of given degree and diameter.
\end{abstract}

Keywords: regular graph, degree/diameter problem, extremal graph.

2010 Mathematics Subject Classification: 05C35, 05C12.

\section{REFERENCES}

[1] E. Bannai and T. Ito, On finite Moore graphs, J. Fac. Sci. Tokyo Univ. 20 (1973) 191-208.

[2] E. Bannai and T. Ito, Regular graphs with excess one, Discrete Math. 37 (1981) 147-158. doi:10.1016/0012-365X(81)90215-6

[3] R.M. Damerell, On Moore graphs, Proc. Cambridge Philos. Soc. 74 (1973) 227-236. doi:10.1017/S0305004100048015

[4] P. Erdös, S. Fajtlowicz and A.J. Hoffman, Maximum degree in graphs of diameter 2, Networks 10 (1980) 87-90. doi:10.1002/net.3230100109

[5] A.J. Hoffman and R.R. Singleton, On Moore graphs with diameter 2 and 3, IBM J. Res. Develop. 4 (1960) 497-504. doi:10.1147/rd.45.0497

[6] M. Knor and J. Širáň, Smallest vertex-transitive graphs of given degree and diameter, J. Graph Theory, (to appear).

\footnotetext{
${ }^{1}$ The author acknowledges partial support by Slovak research grants VEGA 1/0781/11 and APVV-0223-10.
} 
[7] M. Miller and J. Širáň, Moore graphs and beyond: A survey of the degree-diameter problem, Electron. J. Combin., Dynamic survey No. D14 (2005), 61pp.

Received 7 March 2012

Revised 17 September 2012

Accepted 2 October 2012 